\title{
The Cultural Challenges of Managing Global Project Teams: a Study of Brazilian Multinationals
}

\author{
Ivete Rodrigues', Roberto Sbragia ${ }^{2}$
}

\begin{abstract}
The internationalization of Brazilian companies brings a new reality: the need for implementation of global projects that bring, in turn, the challenge of managing multicultural teams. Since this is a recent phenomenon with little theoretical development, this study sought to understand the relationships between cultural characteristics and management teams of global projects in Brazilian multinationals. To carry this discussion forward, we studied six cases of Brazilian multinational companies, with the aim of deepening the understanding of the management of global teams, involving the planning, deployment, development and management of human resources. Among the projects studied, it was found that there is very little concern with the specific issue of multiculturalism and little inter-cultural incentive to the development of team members, which ends up hindering the construction of a global mindset, important for the Brazilian multinational companies to perform successfully abroad. Faced with this situation, each of the managerial processes mentioned were presented with a number of actions to be undertaken by the project manager in three different dimensions: the project itself, the organization and the global environment. The work contributes, thus, to enable Brazilian multinational companies to manage their global teams in order to maximize the advantages of global teams, such as increased creativity and innovative capacity, but avoid the problems that multiculturalism can bring, ranging from conflicts between people to project failure.
\end{abstract}

Keywords: project management; global projects; business internationalization; culture; inter-cultural competence.

'FIA Business School, Rua José Alves da Cunha Lima, I72, São Paulo, Brasil, CEP: 05362-070. Phone: (55-II) 38I 8-4035.

E-mail: iveter@fia.com.br

${ }^{2}$ School of Economics, Business and Accounting at the University of São Paulo, Av. Prof. Luciano Gualberto, 908, Cidade Universitária, São Paulo, Brasil. CEP: 05508-900. Phone: (55-I I) 38I8-4048. E-mail: rsbragia@usp.br

ISSN: 07 I8-2724. (http://www.jotmi.org)

Journal of Technology Management \& Innovation (C) Universidad Alberto Hurtado, Facultad de Economía y Negocios. 


\section{Introduction}

By 1980's, developing countries hardly recorded outflows of Foreign Direct Investment (FDI). This reality has changed since then, thanks to the significant increase in the importance of these countries in the global economy and the competitiveness that their firms reached. An example of that is the global crisis of 2008, which caused a drop in FDI outflows from developed countries, but not in the development. In Brazil it has been no different, in that 2006 marked the year that, for the first time, the flow of Brazilian investments abroad exceeded foreign investment in Brazil (MDIC, 2009). This systemic process of internationalization of Brazilian companies has led to a significant increase in projects developed across national borders. This new reality introduces an unprecedented range of management challenges, from the moment in which individuals from different organizations in different countries and with different value systems need to share authority, responsibility and decision making (Shore \& Cross, 2005). The ability of multinational corporations to integrate resources, knowledge and assets globally dispersed, becomes, in this new context, one of its key competitive advantages. To that end, a major challenge for managers is to seek the cooperation and coordination between task forces and project teams through social networks and human interactions between geographically distant individuals (Atamer and Schweiger, 2003).

If on the one hand the cooperation and coordination of project teams is a global challenge, on the other hand the cultural issue is also identified as the cause of failures in projects of this nature. Because each individual carries their culture (beliefs and values), the project manager needs to be aware of the impacts of cultural diversity on the performance of the project. However, despite such importance, research shows that the subject has been poorly studied by authors in the field of project management (Leybourne, 2007; Rodrigues et al., 2009; Henrie and Sousa-Poza, 2005). Even studies in the area of people management with an organizational focus, cultural aspects of people management in the international level appears as an emerging theme and lacking in publications, and the existing literature deals, in part, with issues related to expatriate professionals to foreign subsidiaries, not taking into account the specificity of managing global projects (Barreto et al., 20l I). This gap in the literature presents challenges for researchers who need to incorporate theories and concepts developed in other disciplines in order to build knowledge and methods applicable to project management.

Encouraged by the relevance of the subject, both from the point of view of the necessity of Brazilian multinational companies to undertake global projects, as well as the lack of literature on the management of multicultural teams, the present authors conducted a study to identify, among the cultural characteristics of the countries, which would be those that would impact over the performance of such teams (Rodrigues and Sbragia, 20I I). Once identified the existence of such impacts, this earlier research pointed to the need for qualitative research that sought to understand how such impacts are effectively managed by leaders of global projects. Having set this panorama, the aim of this study is to explain, through case studies, as is the process of managing global teams in Brazilian multinationals. From these results, we propose a framework that takes into consideration the need for management of cultural aspects that impact the performance of global teams.

\section{Conceptual Background}

\section{National cultures and Intercultural Competence}

The impact of national cultures in the management of organizations has been a constant target of scientific studies. Hofstede (2003), one of the great scholars of the subject, argues that the globalization of business does not necessarily lead to the globalization of culture and, therefore, generic managerial solutions may not be useful in specific cultural contexts. In other words, management solutions, to be successful, must take into account cultural differences that govern human societies. According to this author, culture works as a mental programming constituted by patterns of thought, feeling and potential actions that each individual carries. It is a result of continuous learning and predetermines partially the behavior of human beings. Despite the enormous diversity of minds, there is a structure that serves as the starting point for mutual understanding and which is composed by dimensions of cultural differences. Besides Hofstede (198I), several authors, including Hall (1990), Trompenaars (1994), Schein (200I), Kabasal and Bodur (2004) and House (2002) pored over the study of the different dimensions of national cultures. Among them it is possible to say that there is more complementarity than contradictions. For this study, we adopted the concept and dimensions proposed by Hofstede (2003) that allow comparisons between the cultures of various countries.

The cultural dimensions proposed by Hofstede (2003) are called: a) Power distance (PDI), b) individualism versus collectivism (IDV) c) masculinity versus femininity (IMAS), d) uncertainty avoidance (UAI). This set forms a four-dimensional model of the differences between national cultures. Each country, according to this model has different results for each dimension. There is a fifth dimension - the longterm direction and guidance in the short term - that was not part of the previous model, which was built later by Hofstede in order to capture value from the perspective of Eastern society. This last dimension, it contains a lower amount

ISSN: 07 I8-2724. (http://www.jotmi.org)

Journal of Technology Management \& Innovation (c) Universidad Alberto Hurtado, Facultad de Economía y Negocios. 
of data available from different countries was not used in this study (for a greater understanding of cultural dimensions, see Hofstede, 2003 and Rodrigues \& Sbragia, 20I I).

The Brazilian national culture is understood as high hierarchical distance. Both upper and subordinates believe that ignoring hierarchical levels, although it is best to carry out the work, it is a sign of insubordination. Brazil may be a more collectivist than individualist country, albeit not as sharp as it witnesses in relation to the hierarchical distance and control uncertainty. In relation to femininity and masculinity, Brazil's position is dubious, but with a tendency towards femininity. In this case, the professionals have lower results orientation. Prevail care for others, equality, well-being and quality of life. Finally, Brazil is considered a country with high control of uncertainty, in which people feel uncomfortable with ambiguity. On the desktop no greater career stability and people feel an emotional need for rules, even though they are ineffective. Brazilian authors corroborate, in large part, the theoretical findings of Hofstede (20II), particularly with regard to the hierarchical distance and control uncertainty (Alcadipani and Crubelatte, 2003;Almeida, 2007; Freitas, 1997).

\section{Cultural distance between countries}

The concept of cultural distance is from the term psychic distance, coined by Johanson and Vahlne (2003). For these authors, the psychic distance is the sum of factors such as the difference between language, education, legal and business practices, culture etc., That interfere with the flow of information between markets. Companies tend to do international business, initially with smaller markets psychic distance, only to enter other markets.

Based on extensive research by Hofstede in 50 branches of IBM, whose results were commented in the previous section, Kogut and Singh $(1988,2008)$ created an index of cultural distance, defined as the degree to which a firm is uncertain the characteristics of an international market. The contribution of the authors was considered innovative in that it managed to translate the cultural features a numeric index that allows comparison of the cultural distance between countries. This index is based on the deviation of each of Hofstede's dimensions in relation to the classification of the target country. These deviations are then corrected for differences in the variance of each dimension, also calculating the arithmetic mean. Importantly, Kogut and Singh (1988) deal only with cultural distance. The concept of psychic distance is larger, since it includes other dimensions such as political, geographical and economic (Silva and Rocha Figueiredo, 2007; Cuervo-Cazurra 2007; Ghemawat , 200I). The projects in this study had their degree of cultural distance measured according to the proposal of Kogut and Singh (1988).

\section{Global Projects}

Projects in their generic definition are temporary endeavors undertaken to create products, services or unique results. Their features are temporality, which means that every project has a beginning and a set end, the uniqueness of its products, services, or results and progressive development, which means developing in steps and continuing by increments (PMI, 2008). Domestic and global projects are common in relation to the temporality of the effort, the uniqueness and progressiveness, but differ in the location: the first occurs globally, while traditional projects occur locally.

Global projects may be characterized also as structures, temporary organizations designed to achieve a common goal and whose results come from horizontal cooperation within or between organizations (Chevrier, 2003). They involve multiple locations, entities, organizations and business units (Lientz and Rea, 2003). Likewise, the location of the stakeholders can be a way to differentiate between domestic and global projects. In the latter, unlike the former, the stakeholders are spread across different countries. It is the systematic analysis of stakeholders that will reveal whether a project will require treatment as international (Cleland and Gareis , 2006). In the idea of Govindarajan and Gupta (20I I), global teams are those formed by individuals of different nationalities, working in different cultures and organizations, who gather, in a given period of time, to coordinate some aspect of multinational operation on a global basis.

Based on these different definitions, global projects in this study were defined as those that carry the characteristics of a domestic project (temporality, singularity and progressivity), but have, in their teams, individuals from different countries, where teams may be co-located or distributed.

\section{Managing Global Teams}

In the literature on the human resource management in the organizational context there is a relative consensus on the processes to be developed. From the tactical-operational standpoint, the manager's role is focused on functional issues such as recruitment, selection, development, evaluation and compensation, thus exploiting the impact of people management practices on individuals (Barreto, 20I I). The complexity of operating in different countries and of employing workers of different national categories is what differentiates traditional HRM from international management. In international processes encompass concerns such as managing expatriate employees and implementation, comparison and adjustment of management practices of people in different countries where the subsidiaries are (Homen \&Tolfo, 2008). The best way to manage the differences between the countries is to adapt organizational policies for the vari- 
ous national contexts, as some policies may be effective in one country but not in others. This reasoning also applies to people management policies, which must be flexible, able to deal with differences, which indicates a great need for observation of demographic and cultural differences (Nishii \& Özbilgin, 2007).

Regarding the management of human resources within specific projects, according to the Project Management Body of Knowledge (PMI, 2008), it is the manager's job to put the following processes into practice: a) human resource planning: identify, measure and relate the needs of skilled manpower for the project during the time of execution of the project, b) hiring or mobilization of the project team: select and allocate the workforce required for execution of the project, c) development of Project Team: conduct training to improve skills and interaction of team members in order to run the same project activities with productivity, quality, safety and timely contract, e) Manage the project team: control productivity, quality of work, safety and achievement within the contract terms. Also involves monitoring the behavior of the team, providing feedback, solving problems and coordinating changes that aim to better project performance.

With regard to project oriented organizations, there is another important step in the model which is not predicted in the PMBOK (PMI, 2008) - the demobilization of staff. It is, according Huemann et al. (2008), the process rarely discussed in the literature on project management or on human resource management. It is at this stage that the organization needs to define the next steps regarding the professionals. It is necessary to decide whether a particular professional will be immediately allocated to a new project, a project that still start and go where his skills will be best used, or if he will be dismissed because there are no projects he can be allocated to. There are organizations that use the period in which the employee is not involved in projects for training and development or to assist in the tasks of the project management office. Anyway, it is a moment that causes anxiety for professionals, due to the uncertainties involved.

The appointment of persons to global projects has strategic importance and can influence the ability of the organization to retain their talent. Organizations must consciously allocate people based on previous assessments that take into account not only the availability but also the specific development needs, knowledge and international experience of the professionals involved. The development team usually involves training and feedback throughout the project, but few managers are able to deal with other needs of professionals, for example, support for career management. The timing of projects is a critical issue for the management of both global and domestic teams. Being temporary organizations, each time a new project is started, the configuration of the or- ganization's human resources must adapt. This lack of continuity makes the planning of human resources in global projects complex, because it involves not only the expatriation but also the repatriation of professionals, often in a short period of time. Regarding the performance of the teams, there are no results that demonstrate that the performance can be negatively impacted in environments of international projects when compared to domestic projects, especially in the beginning. Performance is improved and can be even higher when the members of these multicultural teams have become accustomed to collaborate and develop strategies to overcome cultural and linguistic barriers. Therefore, the manager has a role to play in developing teams, so that this point of inflection in performance be obtained as soon as possible (Human et al, 2007; Comu et al, 20I I).

Nurick and Thamhain (2006) offer a number of recommendations for the process of developing global teams throughout the lifecycle of the project. At the beginning of the project, the manager should seek the involvement of staff in order to create a favorable environment for project performance, as people feel more committed to the outcome to be achieved. The appropriate definition of the interfaces, responsibilities with the duties, authority relationships, communication channels and work protocols must be developed and information, shared. In the allocation and organization of teams is important that leadership is carefully defined early in the project, as the credibility of the leader with the team, with senior management and stakeholders is crucial for the management and integration of different tasks that are required to achieve the project. The construction of an image of high-performance project is crucial and requires organizational support, project visibility and reward system for team members to attract qualified professionals. Throughout the project it is important to carry out team development sessions, such as brainstorming, exchange of experience, creating a relaxed and informal atmosphere to discuss the needs of the project.

\section{Cultural Impacts}

In practice, the cultural dimensions have significant implications for managing global teams. By analyzing the cultural differences management styles, preferences and motivations of team members can be identified. Hofstede (1983) argues that the dimensions of individualism and hierarchical distance are very important to understand how organizations operate in different parts of the world, especially with regard to project management, pointed out the following aspects. In the case of individualism, the author points out that, in projects, it is common for the task come before intercourse. Relationships are peripheral, temporary and fluctuating. In individualistic cultures it works very well. In more collectivist cultures, it is likely that people feel a certain loss 
of identity when removed from its functional group to work on temporary project teams. Regarding hierarchical distance, points out that projects in general are smaller structures within a larger structure. The hierarchy in the context of the project, is not the main criteria in making decisions. Furthermore, most of the team members have two bosses: the functional leader and the project manager. People therefore need to have a tolerance for ambiguity and the ability to resolve conflicts, focusing on the interests of the project and not about hierarchy.

With respect to the expatriation of those involved in global projects, the cultural dimensions of Hofstede also have relevance. For example, a culture with individualistic orientation will have certain cultural clashes in a tiny country with individual guidance (Valmer and Palmer, 2005). Companies with lower hierarchical distance organize their projects more informally, while those of high hierarchical distance need to clearly define the power relations. Individualism makes communication between members one-to-one type and closed, while in collectivist countries it is multiple and open (Milosevic, 2002). The risk tolerance makes supplies management and contracting more based on partnership while risk aversion requires formal relations based on rules to be followed. Another example refers to the dimension control of uncertainty. The low control uncertainty is appropriate when seeking a results-oriented approach, where the leader is a facilitator, establishes minimum standards and promotes an open learning process. High control of uncertainty is indicated when there is need for security. In this case, the leader is a specialist who makes the rules clear and fosters a structured learning process.

Higgs (1996) points out that each dimension has its managerial advantages, depending on what is sought. While the high hierarchical distance is important when discipline is needed, low distance requires responsibility and self-management by the team members. While individualism promotes greater mobility management, collectivism is related to greater commitment. When precision is needed, high control of uncertainty is beneficial, but innovation benefits more in environments where uncertainty control is lower. Masculinity is related to the efficiency and mass production (operating environment) and femininity is related to personalized or non-routine activities.

Rodrigues and Sbragia (20II) in a study developed under Brazilian multinational global projects, conclude that there is a relationship between cultural characteristics and performance of teams and global projects of Brazilian multinationals, specifically when it comes to human performance, defined by the authors as satisfaction, commitment, creativity and confidence. The hierarchical distance was related to high performance. However, when the cultural distance is high, femininity gains importance in relation to the performance of the teams. Also in relation to the hierarchical distance, it was found that projects whose members have more homogeneous cultural characteristics, there is a higher probability of success, confirming the aforementioned Nordic theoretical approach. There were no relationships between cultural characteristics and technical performance (the service time, cost and quality).

\section{Intercultural Competence Management}

There are fundamental aspects to be considered in the selection of international talent, such as previous experience in interacting with other cultures, experience in international travel, interest in international work and openness to new experiences. Aspects such as intercultural skills, cultural intelligence, global mindset, cultural flexibility and low ethnocentrism are also important (Tariquea, Schulerb, 2008). In a study by Puck, Rygl and Mohr (2008), the level of sensitivity of managers to cultural issues and organizational support are contributing factors to adapt to international contexts. The existence of rewards also has its weight, but restricted to the satisfaction of the manager. Language proficiency, age, and previous experience in similar jobs have lower weight.

Therefore, intercultural competence of the global project manager is of paramount importance. This competence is defined by Johnson, Lenartowicz and Apud (2006) as the effective action of an individual based on his repertoire, allowing one to work successfully with people from different cultural backgrounds, either in their country or abroad and is a factor of success in the internationalization process of firms and global project management. The more one knows the culture of the host country, the less cultural distance and the greater the chance of success in the company's international undertaking. For Higgs (1996), the skills necessary for companies that have ventured into the international arena are: a) building an awareness of their own culture and cultural differences, b) the construction of knowledge of the impact of cultural differences, as well as relative strengths and weaknesses of the different cultures, $c$ ) the development of skills to identify the impact of cultural differences in management and behavioral adaptation in order to achieve effective results. Regarding people, some necessary attributes include traits such as ambition, courage, curiosity, determination, enthusiasm, integrity, judgment, loyalty, perseverance, self-development, tolerance for ambiguity, among others. The personal competence, which encompasses the skills and attitudes, is translated by the individual's ability to adapt to different norms and cultural contexts, to manage stress and resolve conflicts. It involves a self-examination of one's own mental programming and how it differs from other individuals. For such, one needs to know how cultural values are learned and learn to compare and contrast the different 
cultures. Intercultural learning does not mean that the individual should change his culture, but one needs to realize that there are other ways to see things that are equally valid. For intercultural interaction to be effective, this compromise between their own culture and the other needs to be established (Bartel-Radic, 2006).

\section{Method}

In the first part of this article, a brief literature research was presented, from which were extracted the theoretical assumptions relevant to the objective and the research problem of this study and that based the research model presented in Figure I.

The model assumes as theoretical propositions that the processes of managing global teams are influenced by organizational processes of human resource management, but have specific characteristics that must be considered. The adapta- tion of the traditional personnel management is important to the success of global projects and should include aspects such as international selection, training, among others. There are influences of cultural factors that need to be taken into account so that the global projects have more chances of success. Relationships can be positive and / or negative and knowledge of them is essential to the performance of the teams. Given that the processes of managing teams are cyclical and not linear, the management of intercultural knowledge obtained in various global projects implemented by companies is important for the continuous improvement of global project teams. The need to understand the subjective aspects involved in such relationships, such as understanding the context of the organization, perceptions of those involved and the dynamics of group interactions, prioritized the choice for qualitative method. Table I summarizes the main methodological procedures and the following items provide details about them.

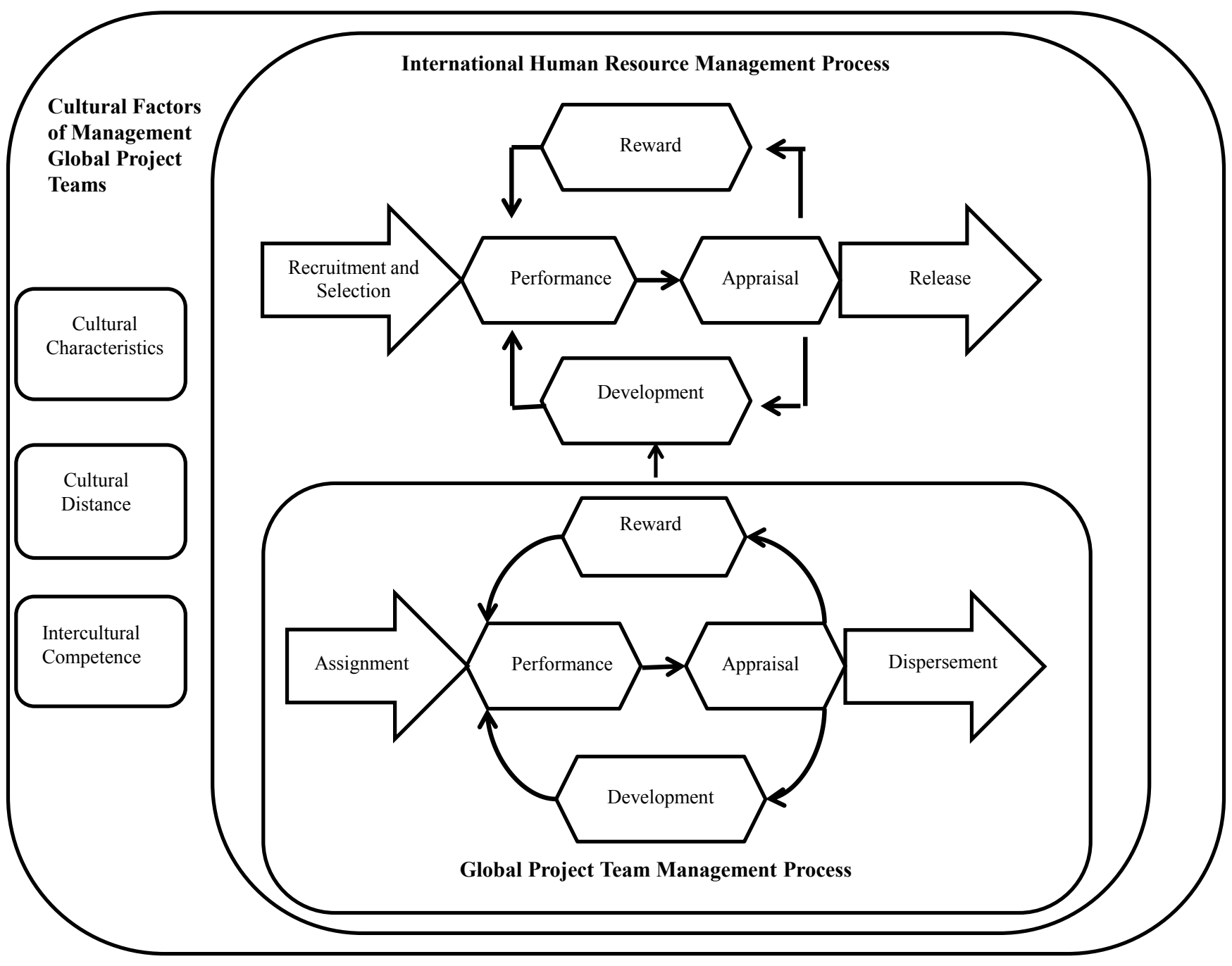

Figure I - Model Study (adapted from Huemann et al, 2006).

ISSN: 07 I8-2724. (http://www.jotmi.org)

Journal of Technology Management \& Innovation (C) Universidad Alberto Hurtado, Facultad de Economía y Negocios. 
Given the qualitative nature of the study, the method used was the case study, conducted in real global projects of Brazilian multinationals, through direct contact between the researcher and the situation under study. According to Eisenhardt (1989), a number greater than ten cases for qualitative studies can generate theoretical saturation, i.e., adding new cases do not correspond to new relevant data.

In Brazil, at that time, there were about 70 multinational companies of national capital (Fleury, 2007; FDC, 2008). From consulting such companies, six cases were defined (global projects) considered representative, whose characteristics are consistent with the theoretical definitions adopted in this study and previously reported. These global projects occurred within large companies with high turnover, having teams large (over 20 people), with multicultural characteristics and with different degrees of cultural distance, ranging from low to high degree of cultural distance. It is believed, therefore, that the sample is representative and that data are meaningful context before the studied population. The cases are presented in Table 2, where there is information regarding countries involved in each project, the cultural dimensions (Hofstede, 200I) and the degree of cultural distance (Kogut and Singh, 1988).

Key informants were managers of the projects, to ensure the fulfillment of the criteria for involvement with the project, organizational knowledge and professional experience. The interviews were conducted in person by the researcher, since, according to Gil (2002), this practice makes the results more reliable. It ensures, on the one hand, that the informant is actually qualified to answer the questions, and secondly, it makes them more likely to provide more reliable answers. All interviews were recorded and later transcribed. After reading each one, the data were organized according to the categories of analysis presented in the study model (planning, deployment, development, management and demobilization of staff). The qualitative analysis, unlike the statistical approach, selects information that has the potential to demonstrate, confirm, refute or challenge existing theories (Eisenhardt, 1989). Thus, for the analysis of these data, we used the logic of literal replication, which seeks to verify similarities and differences between cases and theoretical replication, which seeks to check for contrasting results with those theoretically recommended. Therefore, instead of seeking statistical representativeness, we sought an analytical representativeness (Yin, 200 I).

\section{Results and Discussion}

How do Brazilian multinationals manage project teams before the global cultural impact? To answer this question, the qualitative data obtained from interviews with managers of six global projects are discussed in this chapter. Knowing that culture influences the performance of project teams (RODRIGUES, 2010), the question arises on how these teams are managed and how cultural issues are handled by the project manager.

\begin{tabular}{|l|l|}
\hline Nature Study & Exploratory Qualitative \\
\hline Type of Search & Case Study \\
\hline Population & 70 Brazilian multinational companies considered to be actively managed abroad. \\
\hline Sample & $\begin{array}{l}\text { Intentional non-probabilistic, selected by convenience among 70 Brazilian multina- } \\
\text { tional companies identified in the study. }\end{array}$ \\
\hline Sample Size & 6 Global Projects in 6 different companies of the population \\
\hline $\begin{array}{l}\text { Unit of analysis or } \\
\text { stocks }\end{array}$ & Global Projects \\
\hline Data Collection & Interviews applied personally by the researcher, with a duration of I20 minutes each. \\
\hline Key Informant & Managers of Global Projects \\
\hline Data Treatment & $\begin{array}{l}\text { - Listening and transcribing the interviews } \\
\text { - Reading the transcribed material } \\
\text { - Classification of data in view of the analytical categories }\end{array}$ \\
\hline Data Analysis & $\begin{array}{l}\text { - Individual analysis of each case; } \\
\text { - Analysis of the cross-cases; } \\
\text { - Literal replication; } \\
\text { - Theoretical replication. }\end{array}$ \\
\hline
\end{tabular}

Table I - Summary of Methodological Procedures

ISSN: 07 I8-2724. (http://www.jotmi.org)

Journal of Technology Management \& Innovation (c) Universidad Alberto Hurtado, Facultad de Economía y Negocios. 


\section{Planning and Deployment Team}

As it was seen in the conceptual review, in the selection of team members, the question of jurisdiction is considered critical since it must define the skills and capabilities required to complete project activities. If there is a prior identification of possible incompatibilities, proactive responses such as training and hiring other professionals, can be given. It was also argued that in global projects intercultural competence is a critical success factor of the teams. Despite recognition of potential cultural impacts, in five of the six projects studied it appears that they are not taken into consideration when planning the team. Only 5 indicated that the project makes a preliminary survey of the possible cultural clashes. In the allocation of team members, technical skills overlap intercultural competences. To compensate for possible deficiencies related to intercultural competence, experienced managers are chosen, those who already have a greater experience in project management. When the companies performed greenfield, i.e., it already has on its staff human resources from the host country, a professional is responsible for making a cultural bridge.

Regarding the definition of roles and responsibilities, an important part of the planning team, it was found that in matrix structures, project case I, Peruvians members had difficulty dealing with authority. This is probably due to the fact that Peru, like Brazil, is a country of high hierarchical distance. However, the project was conducted with greater authority of the project manager than the functional manager. So people used to responding to a single authority may have felt uncomfortable in a matrix structure, since this structure requires more than a new organizational structure, a new mental attitude. In projects with high cultural distance, project case 6 , as there was no pre-planning of the possible cultural problems, the team that, a priori, would be distributed, had to be co-located in the United States so that the various cultural problems that emerged could be treated closer, lest the project be unsuccessful. Such problems, unlike what happened with project I, were based on the non-acceptance by Americans and Canadians, of the authority of the Brazilian manager.

The authors of the study also pointed to the importance of the process of deployment and recruitment of staff, as the project manager could not deploy the necessary human resources, the project may be affected in terms of schedule, budget, customer satisfaction, quality and risks. When it comes to Latin American countries (Projects I and 3) and Africa (Project 6) there was report of a difficulty arising from the imposition of the host countries of hiring a minimum quota of local professionals, since it brings problems to the project because the professionals available in general do not have the appropriate profile, due to educational deficiencies of local workforce. People have to be trained in the workplace. This fact brings negative impacts to project deadlines, which take much more time than expected to complete. When one knows this in advance, it is possible to plan more realistically. However, many of these problems are only perceived when the project is already underway; i.e., there is a lack of advance planning.Another problem reported is that African countries in general are not attractive to Brazilian professionals, due to conflict, lack of infrastructure, health and education, as well as the high rate of mortality from

\begin{tabular}{|l|l|l|l|l|l|l|}
\hline Project & Countries & HDI & IDV & IMAS & ICI & GDC \\
\hline Project I and 3 & Brazil & 69 & 38 & 49 & 76 & I.25 \\
\hline & Peru & 64 & 16 & 42 & 87 & \\
\hline Project 2 and 4 & Brazil & 69 & 38 & 49 & 76 & 8.67 \\
\hline & USA & 40 & 9 I & 62 & 46 & \\
\hline Project 5 & Brazil & 69 & 38 & 49 & 76 & 4.83 \\
\hline & Angola & 64 & 27 & $4 I$ & 52 & \\
\hline & Mozambique & 64 & 27 & $4 I$ & 52 & \\
\hline & Colombia & 67 & 13 & 64 & 80 & \\
\hline Project 6 & Brazil & 69 & 38 & 49 & 76 & 14.98 \\
\hline & USA & 40 & 91 & 62 & 46 & \\
\hline & Canada & 39 & 80( & 52 & $48)$ & \\
\hline
\end{tabular}

Table 2 - Project participating in the qualitative study

PDI = Power Distance Index (Hierarchical) IDV: Individualism vs. Collectivism Index; MAS = Masculinity $x$ Femininity Index; UAI = Uncertainty Avoidance Index; GDC = Degree of Cultural Distance. Scale of 0 to 100. The closer to 100, the higher the hierarchical distance, individualism, masculinity, and the degree of control uncertainty

ISSN: 07 I8-2724. (http://www.jotmi.org)

Journal of Technology Management \& Innovation (c) Universidad Alberto Hurtado, Facultad de Economía y Negocios. 
endemic diseases. This creates both a challenge in the selection and allocation of people, as in the maintenance of the same project. What is necessary, in this case, is an incentive plan developed by the Department of Human Resources. In these projects, since the cultural distance is low, most of the problems are related, apparently, to geographical and economic distance. Some projects try to narrow that gap by sending missions that will make the preliminary survey of the situation of the host country, but this survey takes into little account cultural issues, and insider information on infrastructure, economy, etc.

\section{Team Development}

In the previous section, it was found that there are problems related to the qualification of people. However, little is invested in their development, especially in cultural aspects. Developing the project team is part of the responsibility of the manager, who should be able to identify, build, maintain, lead and inspire project teams to achieve high performance. The literature indicated that teamwork requires the manager to provide challenges and opportunities, provide feedback and support, recognize and reward good performance. Furthermore, this is where conflicts arise, and in global projects the cultural issue gains importance. In this case, it is necessary to develop confidence and manage conflicts productively, in order to seek appropriate solutions.

In the development phase, as indicated by the PMBOK (PMI, 2008), it is important to verify the possible training needs of the project team. Only project 5 made any effort to provide a development of intercultural competence. Nevertheless, this development takes place at the level of information. As seen in the literature, only information is not enough, as it serves only the cognitive dimension of intercultural competences. It is also necessary to develop people in their behavioral skills. The major concern with the development relates to the technical aspects, considered essential to project success. Intercultural learning is left under the responsibility of the professional and the possible conflicts that may arise are not anticipated, but worked on a day-to-day project. The managers of the projects surveyed did not have responsibilities related to promotion, compensation, and training people, leaving it to the functional manager and the human resources department. Confirming the relationships proposed in the model study, the cases demonstrated the importance of a closer relationship with this department, so that issues related to cultural distance may be treated beforehand.

If in the under-developed countries there are difficulties of hiring skilled labor in developed countries (United States and Canada) the reality is different, but still there are difficulties. The professionals are technically well qualified, but the task of team development is difficult, since there are profes- sionals who become accommodated and do not want to be promoted. As the wage gap between the positions is small, these professionals prefer to earn less than take on new responsibilities. In Canada, specifically, full employment means that people have a low commitment to the project, because if they are lad off, they will find a new position quickly. In this context, the project manager is quite challenged in their interpersonal skills. It is important to create an environment of trust, exercising empathy and acting as a facilitator of relationships, while also considering the cultural characteristics of the foreign members.

Regarding remuneration, recognition and skills in general managers of the projects surveyed have little autonomy to perform such functions, which are generally attributed to the functional manager and the human resources department. Apparently, there are no clear policies for expatriation and, in most projects, the professional motivation is less financial and more linked to a possible recognition of the organization and the labor market from the moment an international position is taken. This can confer status to the professional both within the organization and outside of it. These data also corroborate the conceptual propositions presented on the study, noting that there is a need for clear policies for repatriation, so that the talents developed are retained within the organization.

\section{Team Management}

In this section the characteristics of the management of teams of global projects are presented. A conceptual review pointed out that at this stage it is important that the manager track the performance of team members and manage the necessary changes to not affect the outcome of the project. It is here, in this phase, where the difficulties arising from the deficiencies in planning and development of people in intercultural skills are manifested. The case studies corroborate the literature regarding the need for the project manager to have global cultural sensitivity, as it is crucial in the ability to resolve conflicts over the lifecycle of the project.

Regarding the problems faced in managing, project I shows that the high hierarchical distance makes the professionals of the host country have submissive behavior in the project, which is not conducive to creativity and innovation. As the culture of the parent company is making decisions by consensus, not from the top down, people feel insecure in their roles. Also, it takes a while to trust people and feel free to express their ideas. Although Brazil is also a country of high hierarchical distance, it was found that managers seek projects studied, mostly a more horizontal relationship with team members. Officials from other countries do not seem to feel comfortable and have difficulties taking initiatives, already expecting a more directive and formal kind of leadership. 
Project 3, which is developed in the same country as project $\mathrm{I}$, also indicates similar behavior. The relative submission of local partners on the basis of a high degree of respect for hierarchy leads to the need for this type of management too. It is difficult to delegate activities. Many times people say yes when they are asked to perform a particular task, but rather this is loaded with uncertainty. This insecurity in questioning and in treating colleagues as equals can lead to problems of deadline, due to a lack of understanding about the content of the tasks.

Project 2 supports the appointment of a project leader with many years of professional experience, since this type of professional usually has more tolerance and sensitivity to cultural differences. For example, one must have tolerance for conflicts generated by how Brazilians and Americans see the issue of time. Brazilians see time as something elastic, while Americans do not tolerate delays. In this case, the behavioral competence of the project leader is essential to reach a consensus. Project 4 , whose team is distributed, pointed out the difficulties of communication as the major bottleneck for the management team. Although English is the lingua franca, it is clear that the Brazilians make a great effort for the communication to be productive, while the Americans do not operate the same way. If an Americandoes not understand the conversation, communication is compromised and can harm the project. If the team was co-located, this barrier may have been lower.

Other management issues were presented by project 5 . Endemic diseases such as malaria causes the team to have a lot of turnover. Every time an individual has to be repatriated for health reasons, there is a delay in the process of recovery and development of work until the new member is effectively adapted to local conditions. The project does not involve a team of expatriates only, due to the high cost. However, there is a great shortage of local skilled technical manpower, spending considerable time and resources on developing people. Issues of labor laws also lead to a high rate of absenteeism. For example, in countries such as Mozambique, where there is the death of a family member, even 3rd degree relatives are allowed by law to take a week's leave off work.All these are issues that affect the management and to which the project leader must be careful to avoid damage to the project.

Also in relation to project 5 , it was advocated the importance of knowing the culture and being at the project site in order to reverse potential conflicts positively to the project. The company has a management model, but it has been adapted with local partners to not cause estrangements and to reduce the possibility of conflicts. There was disagreement as to project risk. The Brazilian partner thinks the risk is high, due to ethnic conflicts existing in the host country.
Yet the local partner who has been familiar with wars for over 30 years, thinks the risk is low. So it is important to have a strong communication work, which is only possible when the team is co-located.

Another case of difficulty of management was pointed out project 6. In Canada and the U.S. people are not willing to work overtime, as is the case with Brazilian corporate culture. This occurs mainly in the summer, since these countries have a harsh winter and people want to enjoy the sunny days, making the completion of the project within the stipulated time. In the final phase of the project, where the parallelism of activities is intense, it was necessary to hold meetings to convince people to work over the weekend. It was also necessary a process of constant negotiation with the union. Due to resistance from both the local leader of the team members as the new management model that was being implemented, the team members had little autonomy to work alone. If they had to do something alone, the work did not progress satisfactorily. The project leader himself did not feel committed to making the project take off, which led to the need to relocate a Brazilian to be a representative to defend the interests of the matrix in the project. This was an initial resistance that had to be overcome. Therefore, a Brazilian representative who could afford to act as a facilitator was chosen. However, there was also initial resistance to this new team member who, at first, was seen much more as a spy than a facilitator. This resistance was overcome with time, when the project began to perform better and take off. This caused the internalization of the importance of the project delayed because they did not accept a third world country to impose a new way of doing things. But this form was necessary so that the company could have a valid business model for the parent company and all its subsidiaries. From the internalization, there was a breakthrough since both Canadians and Americans are very good planners and executors. Therefore, it was critical to understand the local culture and skills of the different members of the team to take the best advantage for the benefit of the project. Language was also a barrier, as well as reported in project 4, the Brazilian, while not understanding something, makes a great effort to improve communication, but both the Canadian and the U.S., having English as their native language, did not make an extra effort to foster communication. This meant that the meetings between the matrix and the subsidiary were unproductive, to the point of being gradually abandoned. In the literature, the language has been identified as a factor of less impact. This can be explained, perhaps, by the fact that these studies were carried out in developed countries, where the population tends to have a greater command of the English language. Brazilian companies, in this sense, may have disadvantages because of the low proficiency in foreign languages for much of the population and the fact that the mother tongue, Portuguese, is little used in international business. 
When making a joint analysis of the six projects, it seems that those in which the cultural distance is low, the geographical, political and economic distances become more prevalent. In countries where the cultural distance is high, most of the problems stem from conflicts related to different cultures. Finally, it is important to note that cultural differences reported here do not intend to put a country in a position of superiority or inferiority to others, but simply to recognize that differences exist and need to be known and managed to ensure that the project achieves success. When it comes to culture, there is no better or worse, just different. Intercultural competence is precisely to respect the differences. The knowledge of the culture and the recognition of each other's culture is a commitment that must be established between team members so that the cultural interaction occurs in favor of the project.

\section{Demobilization Team Global Projects}

In the conceptual review, the specific management teams were discussed, particularly regarding demobilization. Unlike the routine operations of the companies, projects end and teams need to be relocated. In global projects studied here, the projects coexist with functional activities and, therefore, use the matrix structure. After completing the projects, its members return to their usual functions. Team members who were expatriates are repatriated; outsourced professionals are laid off without extra cost to the organization.

Consistent with the literature, the data indicate how important experiential knowledge is for the creation of an intercultural competence of professionals working in multinational companies with global operations. The transfer

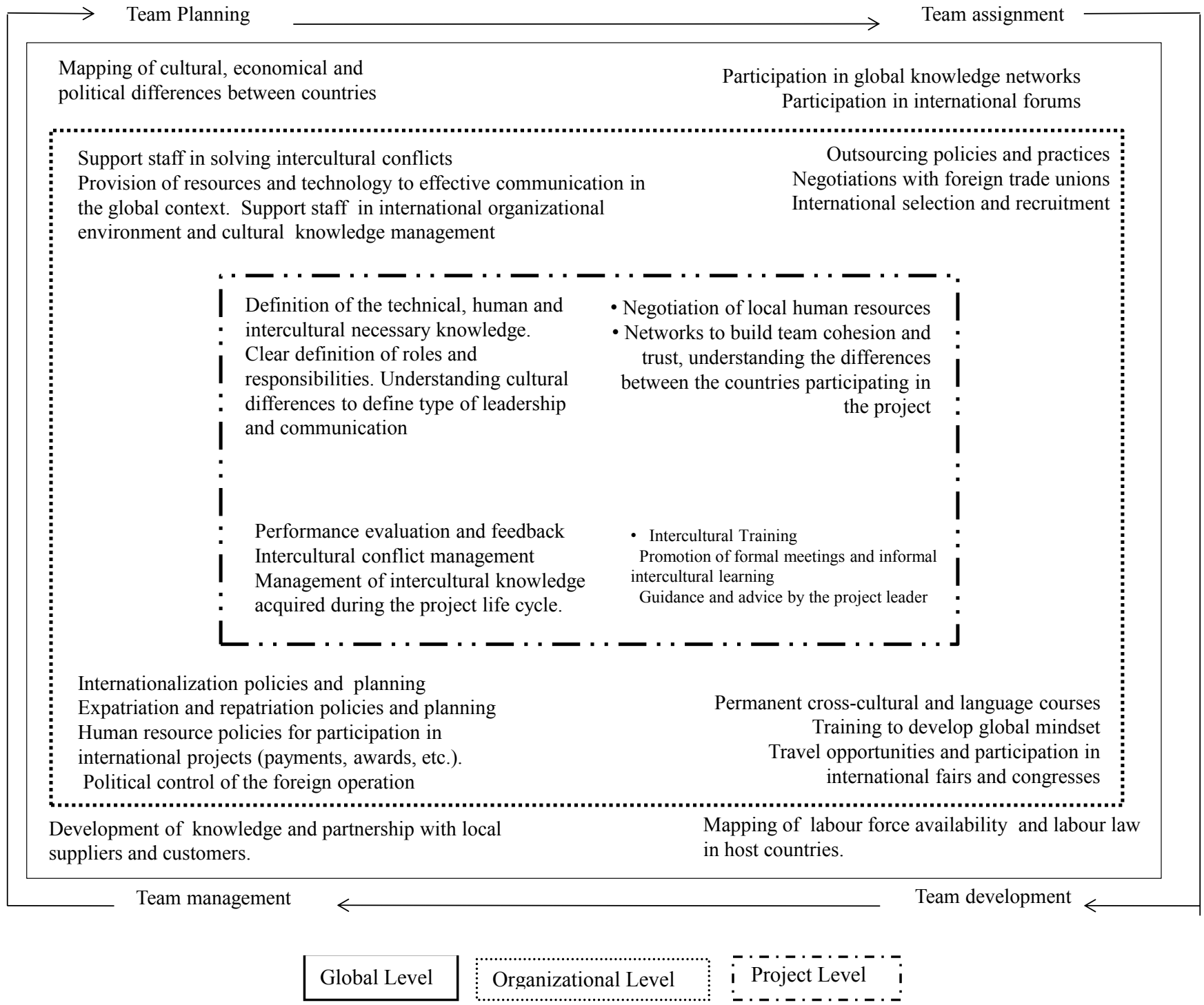

Figure 2 - Framework for study and management teams of global projects. Legend above.

ISSN: 07 I8-2724. (http://www.jotmi.org)

Journal of Technology Management \& Innovation (c) Universidad Alberto Hurtado, Facultad de Economía y Negocios. 
and sharing of knowledge are considered strategic assets for the company. However, all managers are unanimous that the greatest difficulty is the internalization of the knowledge generated, especially those related to international experience and intercultural competence. In general, the most qualified professionals are from the company itself and not outsourced. Still, the investment in terms of training or additional skills obtained through performance in global projects end up not reversing in organizational benefits, as the reuse of knowledge generated in new projects ends up being minimal. Respondents claim that there is a practice of registering lessons learned, but mostly on aspects such as cost, time, quality, contracts and risks. Cultural issues, considered more intangible, are hard to register. To this end, according to respondents, other more permanent actions were needed in the organization, most of which depending on human resources than project managers.

\section{Managerial Implications}

The complexity and delicate interfaces that involve the management of a global team makes it necessary to implement a set of activities that do not rely exclusively on the project manager. They require maturity in project management, whether global or domestic. Besides having adequate staff and best practices in terms of methods and techniques, global projects require that the organization be prepared for their multiple instances to handle complexity and risk. More than ever, collaboration and integration between different areas of the company will be required to account for all the peculiarities of global projects.

The deficiencies observed in managing global teams, both in literature and in case studies presented point to a number of improvement opportunities that can be incorporated by businesses that operate in an international environment. These improvements, however, should be made jointly by all organizational actors linked to the management of global projects. Therefore, the authors propose a framework (Figure 2) which takes into account the environment, the organization and the project.

For example, while the project manager is responsible for the planning process of the team, by the definition of technical and cultural skills necessary it is for the organization to retain talent and maintain a team of qualified professionals, whose participation can be made in a timely manner for the start of the project. Likewise, the project manager is responsible for negotiating the best human resources to the project, but requires that the organization incorporates new criteria to the selection process and recruitment to consider cultural issues with the relevance it has operations and international projects.

\section{Conclusions and recommendations}

In concluding this study, it is important to resume to its purposes. We sought to understand in the light of cultural diversity, how is the process of managing global project teams in Brazilian multinationals in the context of high and low cultural distance. The data presented indicate that there is still little concrete concern with the issue of multiculturalism. Although the project managers recognize, even intuitively, that the cultural characteristics of individuals can affect performance, they are still incipient and rare the activities of planning and development of teams seeking to address the issue. The difficulties are worked in a style of trial and error, with little advance planning and a few actions effectively structured and systemic. The actions also err by superficiality, since, when there are such activities; they are related only to the outer layers of the "cultural onion", which are artifacts -visible and easier to handle, such as clothing, food, social etiquette etc. The deepest beliefs and values are little perceived or worked on. Thus, intercultural knowledge is not internalized by the organization, depending on the experience of executives who are predisposed to work abroad. Defining a global mindset defined in the literature as a crucial point to achieve international success becomes a complex and timeconsuming task. Intercultural competence gains importance in the design of high cultural distance, since the latter reflects a difference in cultural values and environmental variables such as language codes, economics, politics, etc.

Besides the cultural issue, other aspects were considered important as labor legislation, economy, and availability of skilled labor, among others. Accordingly, the data seem to show that the cultural distance is not the only one that affects the performance of the teams, there is a need to consider economic, political and geographical. le, it is necessary a more integrated view of the different aspects challenge the global management teams. There are efficient ways to circumvent these difficulties, either by proper selection of the project leader and other team members, or the development of intercultural competence, either through organizational learning these skills.

As a result of the internationalization strategy, strategies are needed for managing people, where there are definitions as expatriation policies, training and development of the workforce of the country of origin and host countries, international selection of qualified professionals. In light of such strategies, it is up to the project manager to recognize the cultural differences that he will face, and consider them in all phases of the management team, be it planning, mobilization, development, management and even demobilization. Thus, one must go beyond technical skills to also consider intercultural skills necessary to the professionals. Indeed, such skills will benefit the projects, to the extent that can reduce conflicts and facilitate the work of the management team.

ISSN: 07 I8-2724. (http://www.jotmi.org) 
Having laid these conclusions and recommendations of the study, which would be the main theoretical and practical implications? It is noted here that studies of project management are not sufficient to account for the complexity of managing multicultural teams. In global environments, it is necessary to have a more holistic view of the problems, since the sum of the parts is not necessarily equal to the whole. From this arises the importance of engaging scholars, theorists and practitioners responsible for project management and their teams in a broader discussion that relates various disciplines of business administration and organizational theories, management and even people from other areas, as is the case of psychology. That is, we need to move in multidisciplinary project management. The recommendations that were presented in this study seek to follow this direction.

With regard to the consequences for organizations, it must be recognized that the methods and management tools more deterministic, based on processes with inputs and outputs that contributed and continue to contribute to the management of projects and their teams. Incidentally, they represent, in fact, a breakthrough, especially in the case of Brazilian companies, in which project management has generally been treated more informally than systematically. However, such an approach may hinder the understanding of the interactions between the different variables involved in the process of managing global teams. The life cycle of a global project is expanded, since it begins in internationalization strategy and goes to the placement and monitoring of the product and / or service in the new organizational environment or market. That is to say, managing project teams begins before and beyond the end of the project, indicating the involvement of various functional areas such as strategy, people management, information technology management, among others, will bring better results since variables such as communication, training, compensation, etc., are not isolated but rather complementary. Therefore, the management of global projects requires a leader who has access and can transit between the different departments of the company, in order to promote the means of interaction between multicultural professionals, to stimulate intercultural learning and implement training programs to help develop the mindset of global professionals. Apart from the difficulties brought about by cultural differences, there are also opportunities. It is essential to the project manager, to identify potential competitive advantages and disadvantages brought to the team by professionals from different cultures. Regardless of cultural orientation, it can be useful if the manager knows how to take advantage.

Upon completing this study, it is important to note its limitations. One concerns the categories of analysis chosen. Certainly, there are other factors, not only the cultural ones, that must also be considered in managing global projects, such as the economic, geographic and administrative ones.

All pojetos studied were already completed and therefore the time factor may have influenced the perception of respondents. It is possible that during the early stages of a project, the cultural heterogeneity is more pronounced than at the end of it, when it is likely that conflicts have been overcome and that a group identity has already been created. Another restriction concerns the fact that it was captured only the perception of project managers who were, in their entirety, from Brazil. It must also be taken into account that culture, according to several authors, is constantly changing. Data from Hofstede (2003) were collected in the $80 \mathrm{~s}$, and since then, it is possible that Brazilian culture, as well as the other countries in the sample, has been modified. However, having used them as a source of comparison data does not invalidate the results, since recent studies in Brazil also indicate the applicability of cultural dimensions proposed by Hofstede.

These limitations give rise to new possibilities for studies that seek to understand the phenomenon of global teams on new dimensions. For example, longitudinal studies would be interesting, where the process management team was accompanied from the start by the end of the project in order to check for variations in the impact of cultural factors over time. Another possibility is to consider the different types of distance (cultural, political, geographic and economic) as independent variables and not moderating ones. Certainly, such a study would also bring relevant information to the management teams of global projects. Other indicators such as project type and project complexity, among others, could also be considered as moderator variables.

Finally, it is worth noting that the existence of global projects and hence, of multicultural teams, tends to be increasing.Apparently, this is a phenomenon that is here to stay, since it is an important tool in the process of internationalization of Brazilian companies, to the extent that global teams add value through cost savings, acceleration of time and the expansion of capacity for creativity and innovation that diverse sets of skills and multiple views can provide. 


\section{References}

ALCADIPANI, R.; Crubellate, J. M. (2003). Cultura organizacional: generalizações improváveis e conceituações imprecisas. RAE - Revista de Administração de Empresas. Rio de Janeiro, Ed. Fundação Getulio Vargas, vol. 43, n. 2, , pp. 64-77, abr/mai/jun.

ALMEIDA, A. C. (2007). A cabeça do brasileiro. Editora Record, Rio de Janeiro.

ATAMER, Tugrul; Schweiger, David M. (2003). Transnational horizontal project teams. Journal of World Business, vol. 38, p. $8 \mathrm{I}-83$.

BARRETO et al. Emerging Issues in Human Resource Management (20II). Rev.Adm. UFSM, Santa Maria, v. 4, n. I, mai/ ago, p. 215-233.

CLELAND, D. L.; Gareis, R. (2006). Global Project Management Handbook: planning, organizing and controlling international projects. USA, McGraw-Hill, $2^{\mathrm{a}}$ edição.

COMU et al (20II) Dual Impact of Cultural and Linguistic Diversity on Project Network Performance.ASCE Journal of Management in engineering, July.

CUERVO-Cazurra,A. (2007). Las distancias en el proceso de internacionalización: el caso del Banco Santander. Universia Business Review - Actualidad Económica.

EISENHARDT, K. M. (1989). Building Theories from Case Study Research. Academy of Management Review, vol. I4, $\mathrm{n}^{\circ}$ 4, pp.532-550.

FLEURY et al. (2007). Estratégias e Competências das Multinacionais Brasileiras. IN: PGT/USP. Relatório do Projeto Ginebra - Gestão Empresarial para a Internacionalização das Empresas Brasileiras. São Paulo, PGT/USP / FAPESP.

FREITAS,A. B. (1997).Traços para uma análise organizacional. In: Motta, F. C. P.; Caldas, M. P. (Coords.). Cultura organizacional e cultura brasileira. São Paulo, Ed. Atlas.

GHEMAWAT, P. (200I). Distance still matters. Harvard Business Review, september, pp. I37-I47,

GOVINDARAJAN, V., and Gupta, A.k. (200I). Building an Effective Global Business Team. Sloan Management Review, 43, $2,63-71$.

GIL, A.C. (2002). Como elaborar projetos de pesquisa. São Paulo, Editora Atlas, 4a edição.
HENRIE, M.; Sousa-Poza, A. (2005); Project Management: a cultural literary review. Project Management Journal, jun, $\mathrm{n}^{\circ}$ 2, vol. 36 .

HIGGS, M. (1996). Overcoming the problemas of cultural differences to establish success for international management teams. The Performance Management: an international journal. Vol. $2, \mathrm{n}^{\circ} \mathrm{I}$.

HOFSTEDE, G. (1983). Cultural dimensions for project management. Project Management. Feb.,Vol. I, n I.

HOFSTEDE, G. (2003). Culturas e Organizações - Compreender a nossa programação mental. Tradução António Fidalgo. Edições Sílabo. Lisboa, Portugal.

HOMEM I. D.; Tolfo, S. R. (2008). International Management of Human Resources: Compensation and Selection of Expatriates at a Brazilian Multinational. RAC-Eletrônica, Curitiba, mai/ago, v. 2, n. 2, art. 3, p. 20I-2I7.

HOUSE, Robert et al (2002). Understanding cultures and implicit leadership theories across the globe: an introduction to project Globe. Journal of World Business, $n^{\circ}$ 37, p. 3- 10.

HUEMANN et al. (2007). Human resource management in the project-oriented company: A review . International Journal of Project Management 25 (2007), 3 I5-323.

JOHANSON, J.;Vahlne, J. E. (2003). Building a model of firm internationalization. In: Blomstermo, A.; Sharma, D. (Ed.): Learning in the internationalization process of firms. UK, Edward Eldar.

KATZENBACH, J. R.; Smith, D. K. (2005). The Discipline of Teams. Harvard Business Review - The high performance organization. July-August.

KOGUT, B. (2008). Methodological contributions in international business and the direction of academic research activity. In: Rugman,A. M. (org.). Oxford Handbook of International Business. New York, Oxford University Press, pp. 782-8I7,

KOGUT, B.; Singh, H. (1988) The effect of national culture on the choice of entry modes. Journal of International Business Studies, $n^{\circ}$ 19, pp. 4II-432.

LEYBOURNE, S. (2007). The changing bias of project management research: a consideration of the literatures and an application of extant theory. Project Management Journal. Mar, vol. $38, n^{\circ} \mathrm{I}$.

ISSN: 07 I8-2724. (http://www.jotmi.org) 
LIENTZ, B. P.; Rea, K. P. (2003). International Project Management. Academic Press, USA.

MARCONI, M. de A.; Lakatos, E. M. (2000) Técnicas de pesquisa. 3. ed. São Paulo:Atlas.

NISHII, L. H.; Özbilgin. M. F. (2007). Global diversity management: towards a conceptual framework. The International Journal of Human Resource Management, v. I8, n. II, p. I.883-1.894.

NURICK, A.J.; Thamhain, H. J. (2006). Developing multinational project teams. In: Cleland, D.i.; Gareis, R. Global Project Management Handbook. $2^{\mathrm{a}}$ edição, McGrawHill, USA.

PMI - Project Management Institute (2008). Um guia do Conjunto de Conhecimentos em Administração de Projetos. US, PMI.

PUCKA et al. (2008). An empirical analysis of managers' adjustment to working in multinational project teams in the pipeline and plant construction sector. The International Journal of Human Resource Management,Vol. 19, No. 12, December, 2252-2267.

ROCHA, A. M. C da; Silva, M. G. F. da; Carneiro, F. O. (2007). Medindo o construto da distância psíquica. E\&G Economia e Gestão, Belo Horizonte, v. 7, n. I4, p. I-I78.

RODRIGUES, Ivete (20I0). Cultura e Desempenho de Equipes de Projetos Globais: um estudo em empresas multinacionais brasileiras. Tese de Doutorado, FEA/USP.

RODRIGUES, Ivete et al (2007).Avanços Recentes e Tendências na Pesquisa sobre Administração de Projetos: uma revisão bibliométrica. In: XII Seminario Latino-lberoamericano de Gestion Tecnologica, 2007, Buenos Aires. Anais do XII Seminario Latino-lberoamericano de Gestion Tecnológica Altec 2007.

RODRIGUES, Ivete et al. (2006). Internacionalização de Empresas Brasileiras do Setor de Construção: a experiência da Andrade Gutierrez. In: Anais do Ix Semead - Seminários em Administração, FEA/USP, 2006.

RODRIGUES, Ivete; Sbragia, R. (20I2). Culture and Performance of Global-Project Teams: A Study of Brazilian Multinational Companies. In: Wesling, Paul; YU, Oliver. Advances in Technology and Innovation Management. USA, IEEE, vol. I.

SANTOS, A. R. (1999). Metodologia científica: a construção do conhecimento. Rio de Janeiro, Editora DPA.
SCHEIN, Edgar H. Guia de sobrevivência da cultura corporativa. Rio de Janeiro: José Olympio, 2001.

SELLTIZ, C. et al (1974). Métodos de Pesquisa nas Relações Sociais. São Paulo, E.P.U. Ltda., 4a reimpressão.

SHORE, B.; Cross, B. J. (2005). Exploring the role of national culture in the management of large-scale international science projects. International Journal of Project Management. Elsevier, $n^{\circ} 23$, pp. 55-64.

SINGH, N. (2004). From Cultural Models to Cultural Categories: A Framework for Cultural Analysis. The Journal of American Academy of Business, Cambridge, pp. 95-101.

TARIQUEA, I.; Schulerb, R. (2008). Emerging issues and challenges in global staffing: a North American Perspective. The International Journal of Human Resource Management, Vol. 19, No. 8, |397-|4|5.

TROMPENAARS, Fons (1994). Nas ondas da cultura: como entender a diversidade cultural nos negócios. São Paulo: Educator.

VALMER, I. e Palmer, T. (2005). Role of cultural self-knowledge in successful expatriation. Singapore Management Review, Vol 27, I, pp I-25.

YIN, R. K. (200I). Estudo de caso: planejamento e métodos. 2. ed. Porto Alegre: Bookman. 